\title{
KAJIAN KANDUNGAN BAHAN TAMBAHAN PANGAN BERBAHAYA 2018- 2019 SE-KOTA PEKALONGAN DAN IMPLEMENTASI PERDA KOTA PEKALONGAN NOMOR 07 TAHUN 2013
}

\author{
Sujarwo $^{1}$, Rr. Vita Nur Latif ${ }^{2}$, Ardiana Priharwanti ${ }^{3}$ \\ ${ }^{1}$ UPT Puskesmas Kusuma Bangsa, Dinas Kesehatan Kota Pekalongan \\ ${ }^{2,3}$ Prodi Kesehatan Masyarakat, Fakultas Ilmu Kesehatan, UNIKAL \\ Korespondensi : sujarwo124@gmail.com
}

\begin{abstract}
Supervision of food safety in Pekalongan City in 2010-2012 shows 6.27\% of food contains hazardous food additives. Pekalongan City Government policies related to food safety are contained in Pekalongan City Regional Regulation Number 7 of 2013, but their implementation has not been studied. The research objective was to further identify types of food containing dangerous hazardous food additives, to further identify the implementation of Pekalongan City Regulation No. 07 of 2013, and further identify the knowledge and attitudes of food producers in Pekalongan City. This research design is a combination of quantitative and qualitative studies. The results of the research further identified that the types of food that were most often found to contain hazardous food additives were dangerous for the types of preservatives (formalin and borax), namely meatball, indi and cilok types of food; yellow noodles; and terinasi (teri Medan); and otak-otak, while the dangerous hazardous food additives types of dye (Rhodamin B and Methanil Yellow) are Krupukuseg red colored; powdered seasoning; krupuk useg yellow colored; and pudding. Pekalongan City Regulation No.7 of 2013 concerning the Prohibition of the Use of Hazardous hazardous food additives, has been well implemented, but not optimal. Some of the knowledge and attitudes of producers in Pekalongan City already know about food safety.
\end{abstract}

Keywords: Hazardous food additives, food safety, local regulations

\section{PENDAHULUAN}

Dinas Kesehatan Kota Pekalongan (20112013) sebelum tahun 2010 sudah melaksanakan kegiatan pengawasan pangan yang beredar di masyarakat khususnya di sekolah-sekolah. Kegiatan ini dilaksakan atas dasar kuat dugaan beredar pangan dengan kandungan bahan tambahan pangan berbahaya (BTP Berbahaya) khususnya pengawet (boraks dan formalin) dan pewarna (Rhodamin B dan Methanil Yellow). Dinas Kesehatan Kota Pekalongan melaporkan hasil kegiatan pengawasan keamanan pangan tahun 2010-2012 menunjukan dari 2.073 sampel pangan yang diperiksa, $6,27 \%$ mengandung BTP berbahaya/dilarang. Radar Kota Pekalongan (2019) pada 14 Desember 2019 memberitakan bahwa Polres Pekalongan Kota berhasil mengungkap produksi mie basah mengandung formalin di Kota Pekalongan. Informasi ini diperoleh dari salah satu pasar yang disinyalir beredar mie yang diduga dicampuri zat terlarang.

Rahayu dan Susalit (2018) menyatakan bahwa Bahan Tambahan Pangan (BTP) berbahaya ini dapat berpengaruh pada gangguan kesehatan baik secara langsung seperti tenggorokan terasa terbakar, iritasi, sakit kepala serta mual, sedangkan pengaruh tidak langsung (menahun/akumulatif) seperti gangguan sistem pernafasan, gangguan pada ginjal dan hati, gangguan sistem reproduksi dan kanker, serta kematian. Balai Besar Pengawasan Obat dan Makanan (BPOM) di Semarang (2018), berdasarkan hasil pengawasan pangan yang dilakukan, diketahui beberapa pangan yang beredar di masyarakat mengandung BTP berbahaya. Menurut Peraturan Menteri Kesehatan Republik Indonesia Nomor 33 Tahun 2012 tentang Bahan Tambahan Pangan, bahwa masyarakat perlu dilindungi dari penggunaan bahan tambahan 
pangan yang tidak memenuhi persyaratan kesehatan. Penggunaan BTP berbahaya yang tidak sesuai syarat kesehatan, mempunyai pengaruh terhadap derajat kesehatan manusia, serta masyarakat perlu dilindungi dari penggunaan BTP yang tidak memenuhi syarat kesehatan. Peraturan Daerah Kota Pekalongan Nomor 07 Tahun 2013 tentang Larangan Penggunaan Bahan Tambahan Pangan Berbahaya tersebut salah satunya bertujuan untuk meningkatkan kualitas pangan yang menjamin kelangsungan usaha produksi pangan serta menjamin kesehatan, keamanan, dan keselamatan (masyarakat) konsumen.

Berdasarkan studi pendahuluan tanggal 19 Februari 2020, wawancara dengan beberapa pedagang pangan jajanan yang diduga menggunakan BTP berbahaya, di Kota Pekalongan, didapatkan informasi bahwa pedagang/penjual pangan belum mengetahui tentang adanya Perda Kota Pekalongan Nomor 07 Tahun 2013. Masyarakat selaku konsumen belum merasakan manfaat dari perda tersebut, karena mungkin perda tersebut oleh Pemerintah Kota Pekalongan sudah diimplementasikan, tetapi belum optimal dalam menjamin kesehatan, keamanan dan keselamatan masyarakat/ konsumen.

Atas dasar inilah peneliti tertarik untuk melakukan studi kajian tentang jenis pangan yang mengandung bahan tambahan pangan berbahaya yang ada di Kota Pekalongan dan bagaimana implementasi Peraturan Daerah Kota Pekalongan Nomor 07 Tahun 2013 tentang Larangan Penggunaan Bahan Tambahan Pangan Berbahaya, serta pengetahuan dan sikap produsen pangan di Kota Pekalongan dalam memproduksi pangan yang aman.

\section{TINJAUAN PUSTAKA}

\subsection{Pangan}

Undang-Undang Republik Indonesia Nomor 18 Tahun 2012 tentang Pangan, mendefinisikan pangan adalah segala sesuatu yang berasal dari sumber hayati produk pertanian, perkebunan, kehutanan, perikanan, peternakan, perairan, dan air, baik yang diolah maupun tidak diolah yang diperuntukkan sebagai makanan atau minuman bagi konsumsi manusia, termasuk bahan tambahan pangan, bahan baku pangan, dan bahan lainnya yang digunakan dalam proses penyiapan, pengolahan, dan/atau pembuatan makanan atau minuman. Peraturan Pemerintah Republik Indonesia Nomor 86 Tahun 2019 tentang Keamanan Pangan, mendefinisikan bahwa keamanan pangan adalah kondisi dan upaya yang diperlukan untuk mencegah pangan dari kemungkinan cemaran biologis, kimia, dan benda lain yang dapat mengganggu, merugikan, dan membahayakan kesehatan manusia serta tidak bertentangan dengan agama, keyakinan, dan budaya masyarakat sehingga aman untuk dikonsumsi.

Anggrahini (2015) menafsirkan bahwa suatu pangan dikatakan aman apabila bebas dari bahaya yang mungkin timbul karena adanya kandungan cemaran biologis, kimia dan fisik. Bebas yang dimaksud bukanlah bebas atau sama dengan nol atau tidak ada sama sekali. Melalui berbagai alasan yang ada beberapa pangan secara alami mengandung kontaminan ataupun karena faktor tertentu kontaminan tersebut tidak dapat dihilangkan sama sekali keberadaannya dalam pangan.

Surono et al (2018) menjelaskan lebih lanjut bahwa ancaman bahaya kimiawi biasanya jarang diwaspadai karena dampaknya yang jarang langsung, akan tetapi ada beberapa yang memberikan dampak langsung seperti iritasi pada tenggorokan ataupun gejala penyakit umum lainnya. Ancaman bahaya kimiawi bisa saja berasal dari penggunaan bahan tambahan pangan berizin yang melebihi takaran, bahan kimia berbahaya yang dengan sengaja ditambahankan ke dalam pangan seperti zat pengawet (borax dan formalin), zat pewarna (Rhodamin B dan Methanyll Yellow) ataupun bahan peramu lainnya.

\subsection{Bahan Tambahan Pangan}

Peraturan Badan Pengawasan Obat dan Makanan Republik Indonesia Nomor 11 Tahun 2019 tentang Bahan Tambahan Pangan, mendefinisikan bahwa bahan tambahan pangan yang selanjutnya disebut BTP adalah bahan yang ditambahkan ke dalam pangan untuk mempengaruhi sifat atau bentuk pangan, tetapi tidak diperuntukan untuk dikonsumsi secara langsung ataupun sebagai bahan baku pangan. 
BTP secara umum adalah zat yang secara sengaja ditambahkan ke dalam proses pengolahan pangan untuk menghasilkan suatu sifat fungsional tertentu pada pangan seperti peningkat rasa, pengembang roti, pengental pangan dan pengawetan pangan.

\subsection{Bahan Tambahan Pangan Berbahaya}

Peraturan Daerah Kota Pekalongan Nomor

07 Tahun 2013 tentang Larangan Penggunaan Bahan Tambahan Pangan Berbahaya, mendefinisikan bahwa bahan tambahan pangan berbahaya yang selanjutnya disingkat BTP berbahaya adalah BTP yang tidak diperbolehkan sama sekali ditambahkan ke dalam pangan. BTP berbahaya yang dimaksud ini tercantum sebagai bagian lampiran yang tidak terpisahkan dari Peraturan Menteri Kesehatan Republik Indonesia Nomor 33 Tahun 2012.

Anggrahini (2015) menerangkan bahwa penggunaan bahan tambahan non pangan atau bahan tambahan pangan berbahaya ini ditambahkan pada pangan di beberapa kasus, terutama oleh industri pangan rumah tangga dan pangan jajanan di dalam proses pengolahannya. Bahan tambahan pangan berbahaya yang paling sering digunakan oleh industri kecil/industri rumah tangga pada produk pangan olahannya adalah dari jenis pengawet (formalin), jenis pengawet dan pengenyal (boraks) dan jenis pewarna tekstil (Rhodamin $B$ dan MethanylYellow). Menurut Peraturan Menteri Kesehatan Republik Indonesia Nomor 33 Tahun 2012 tentang Bahan Tambahan Pangan, keempat bahan kimia tersebut dilarang penggunaannya dalam produk pangan karena berbahaya bagi kesehatan.

\subsubsection{Formalin}

Anggrahini (2015) menerangkan bahwa Formalin dalam industri kesehatan biasa digunakan sebagai bahan pengawet mayat dan antiseptik untuk membunuh bakteri. Wakefield (2008) dalam Yulisa, et al, (2014) menjelaskan bahwa mengkonsumsi pangan mengandung formalin dapat menyebabkan iritasi dan rasa terbakar pada mulut dan esofagus, nyeri dada, perdarahan gastrointestinal dan gagal ginjal.

\subsubsection{Boraks}

Anggrahini (2015) menerangkan bahwa boraks umum digunakan dalam industri kertas, kayu dan antiseptik. Kamim (2008) dalam Athaya, et al, (2015), menjelaskan bahwa mengkonsumsi pangan yang mengandung boraks dalam waktu yang lama dan banyak dapat menyebabkan gangguan kesehatan, di antaranya kerusakan ginjal, gangguan metabolisme pencernaan, kejang, pingsan, bahkan dapat menyebabkan kematian.

\subsubsection{Rhodamin B}

Anggrahini (2015) menerangkan bahwa Rhodamin $B$ adalah pewarna sintesis berwarna merah keunguan, umum digunakan dalam pewarnaan kertas, tinta dan tekstil. Wijaya (2011) dalam Laksmita, et al, (2018) menerangkan bahwa Rhodamin $B$ memberikan dampak buruk bagi kesehatan antara lain menimbulkan iritasi saluran pernapasan, iritasi kulit, iritasi mata, iritasi saluran pencernaan, gangguan fungsi hati berupa kanker hati dan tumor hati.

\subsubsection{Methanyl Yellow}

Anggrahini (2015) menerangkan bahwa Methanyl Yellow merupakan pewarna sintesis berwarna kuning kecoklatan dan biasa digunakan dalam industri tekstil, kertas dan pengkilap sepatu. Kristanti (2010) dalam kutipan Zuraida, et al (2017) menerangkan bahwa dampak negatif yang terjadi akibat mengkonsumsi pangan yang mengandung zat Methanil Yellow dapat berupa iritasi pada tenggorokan (saluran pernafasan), iritasi pada kulit, iritasi pada mata, dan bahaya kanker pada kandung kemih.

\subsection{Regulasi Keamanan Pangan}

Rahayu dan Susalit (2018) menerangkan bahwa keterjaminan kemanan pangan bagi masyarakat memerlukan sebuah sistem pengawasan yang efektif dan efisien. Sistem kewaspadaan keamanan pangan ini melibatkan berbagai disiplin dan ketersediaan peraturan tentang pangan akan menjadi landasan program pengawasan pangan yang beredar di masyarakat. Beberapa peraturan yang membentuk sistem kewaspadaan keamanan pangan di antaranya meliputi : 
2.4.1. Undang-undang Republik Indonesia Nomor 018 Tahun 2012 tentang Pangan

Negara memiliki kewajiban untuk mewujudkan ketersediaan, keterjangkauan, dan pemenuhan konsumsi pangan yang cukup, aman, bermutu, dan bergizi seimbang, baik pada tingkat nasional maupun daerah hingga perseorangan secara merata di seluruh wilayah Negara Kesatuan Republik Indonesia. Secara lengkap undang-undang ini membahas tentang kedaulatan pangan, kemandirian pangan, ketahanan pangan dan keamanan pangan. Undang-undang ini juga dibuat untuk melindungi dari kemanan pangan saja, tetapi di ranah yang lebih luas dan kompleks.

\subsubsection{Peraturan Pemerintah Republik} Indonesia Nomor 86 tahun 2019 tentang Keamanan Pangan

Peraturan ini menjelaskan bahwa keamanan pangan merupakan salah satu faktor penting dalam penyelenggaraan sistem pangan. Penyelenggaraan keamanan pangan bertujuan agar negara dapat mcmberikan perlindungan kepada rakyat untuk mengonsumsi pangan yang aman bagi kesehatan dan keselamatan jiwanya. Keamanan pangan diselenggarakan melalui: sanitasi pangan; pengaturan terhadap bahan tambahan pangan; pengaturan terhadap pangan genetik; pengaturan terhadap iradiasi pangan; penetapan standar kemasan pangan; pemberian jaminan keamanan pangan dan mutu pangan; dan jaminan produk halal bagi yang dipersyaratkan.

\subsubsection{Peraturan Menteri Kesehatan} Republik Indonesia Nomor 033 Tahun 2012 tentang Bahan Tambahan Pangan

Masyarakat perlu dilindungi dari penggunaan bahan tambahan pangan yang tidak memenuhi persyaratan kesehatan. Peraturan ini lebih mengerucut tentang kemungkinan bahaya kimiawi yang muncul akibat penggunaan/penambahan bahan tambahan pangan yang diizinkan tetapi tidak sesuai takaran dan bahan tambahan non pangan yang dilarang ditambahkan pada proses pengolahan pangan. Bahan tambahan pangan yang diizinkan dalam peraturan ini diatur mulai dari jenis dan takarannya, serta mengatur beberapa jenis bahan tambahan pangan berbahaya yang dilarang ditambahkan pada pangan.

\subsubsection{Peraturan Badan Pengamanan Obat dan Makanan Nomor 11 Tahun 2019 tentang Bahan Tambahan Pangan}

Seiring berkembangnya zaman dan munculnya beberapa bahan tambahan pangan baru hasil dari penelitian dan pengkajian secara ilmiah, maka ditetapkan 26 bahan tambahan pangan baru dari yang semula 19 jenis. Peraturan ini lebih memuat bahan tambahan pangan diizinkan mengenai jenis dan takarannya.

\subsubsection{Peraturan Daerah Kota Pekalongan}

\section{Nomor 07 Tahun 2013 tentang} Larangan Penggunaan Bahan Tambahan Pangan Berbahaya

Penggunaan bahan tambahan pangan yang tidak sesuai dengan persyaratan kesehatan mempunyai pengaruh langsung maupun tidak langsung terhadap derajat kesehatan manusia, bahwa masyarakat perlu dilindungi dari penggunaan bahan tambahan pangan yang tidak memenuhi persyaratan kesehatan. Peraturan daerah ini memuat secara rinci tentang pengawasan, penyidikan dan sanksi dalam pelanggaran terhadap penggunaan bahan tambahan non pangan yang dilarang dipergunakan/ditambahkan pada proses pengolahan pangan.

\section{METODE PENELITIAN}

Desain penelitian ini adalah kombinasi studi kualitatif dengan kuantitatif. Fokus penelitian ini adalah metadata jenis pangan yang mengandung bahan tambahan pangan berbahaya tahun 2018-2019 se-Kota Pekalongan dan Implementasi Peraturan Daerah Kota Pekalongan Nomor 07 Tahun 2013.

Sumber data primer penelitian adalah hasil wawancara dengan informan penelitian melalui pedoman wawancara, sedangkan sumber data sekundernya adalah hasil kegiatan pengawasan keamanan pangan tahun 2018-2019 se-Kota Pekalongan.

Karakteristik informan dalam penelitian yang menjadi sumber informasi diperolehnya data dibagi menjadi: 1) Informan utama sejumlah 4 (empat) informan adalah pemegang program pengawasan keamanan pangan di Dinkes Kota Pekalongan; Dinperpa Kota Pekalongan; dan Dindagkop \& UKM Kota 
Pekalongan. 2) Informan pendamping sejumlah 9 (sembilan) informan adalah produsen pangan skala industri rumah tangga yang berusia 15-65 tahun, proses produksinya ada di Kota Pekalongan, produsen pangan skala rumah tangga yang mewakili jenis pangan yang dicurigai mengandung bahan tambahan pangan berbahaya. Dan 3) Informan triangulasi sejumlah12 (dua belas) informan.

Proses wawancara kepada informan dilaksanakan dengan mematuhi protokol kesehatan pencegahan penularan Covid-19 selama masa pandemi ini berlangsung. Hasil data yang diperoleh diolah dan dianalisis, kemudian disajikan dalam bentuk naratif.

\section{HASIL DAN PEMBAHASAN}

Hasil penelitian yang sudah dilakukan, hingga diperoleh data primer berupa hasil wawancara mendalam dengan para informan penelitian maupun data sekunder hasil kegiatan informan utama terkait kegiatan pengawasan keamanan pangan.

\subsection{Jenis Pangan yang Mengandung Bahan Tambahan Pangan Berbahaya Tahun 2018-2019 Se-Kota Pekalongan}

Hasil penelitian yang diperoleh melalui pengumpulan data sekunder hasil kegiatan uji petik/sampling makanan minuman yang ada di Kota Pekalongan sebagaimana tabel 1. dapat dilihat bahwa lokasi sasaran kegiatan pengawasan keamanan pangan yang dilakukan berfokus pada 3 lokasi yakni di sekolahan, di event-event seperti penjualan takjil bulan puasa atau saat acara pameran di Kota Pekalongan dan di pasar tradisional. Jumlah sampel pangan yang dilakukan pemeriksaan tahun 2018 sebanyak 1.286 sampel dan sampel pangan positif mengandung BTP berbahaya $4,35 \%$. Tahun 2019 jumlah sampel pangan yang diperiksa sebanyak 1.977 sampel dan sampel pangan positif mengandung BTP berbahaya $5,67 \%$

Tabel 1 Rekap Hasil Kegiatan Pengawasan Keamanan Pangan Berdasarkan Lokasi Sasaran dan Parameter Pemeriksaan di Kota Pekalongan Tahun 2018-2019

\begin{tabular}{|c|c|c|c|c|c|}
\hline \multirow[b]{2}{*}{ No } & \multirow[b]{2}{*}{ Lokasi Sasaran } & \multicolumn{2}{|c|}{ Tahun 2018} & \multicolumn{2}{|c|}{ Tahun 2019} \\
\hline & & $\begin{array}{l}\text { Jumlah } \\
\text { Sampel }\end{array}$ & $\begin{array}{c}\text { \% Sampel } \\
\text { Positif }\end{array}$ & $\begin{array}{l}\text { Jumlah } \\
\text { Sampel }\end{array}$ & $\begin{array}{c}\text { \% Sampel } \\
\text { Positif }\end{array}$ \\
\hline 1 & Sekolahan & 1.021 & 3,42 & 1.767 & 4,60 \\
\hline 2 & Event (Takjil,Pemeran dll) & 172 & 0,47 & 120 & 0,67 \\
\hline \multirow[t]{9}{*}{3} & Pasar Tradisional & 93 & 0,47 & 90 & 0,40 \\
\hline & Jumlah Total & 1.286 & 4,35 & 1.977 & 5,67 \\
\hline & $\underline{\text { Jenis Uji }}$ & \multicolumn{2}{|c|}{$\begin{array}{c}\text { Berbanding Total } \\
\text { sampel }\end{array}$} & \multicolumn{2}{|c|}{ Berbanding Total sampel } \\
\hline & Boraks & \multicolumn{2}{|c|}{$1,01 \%$} & \multicolumn{2}{|c|}{$0,30 \%$} \\
\hline & Formalin & \multicolumn{2}{|c|}{$1,79 \%$} & \multicolumn{2}{|c|}{$2,28 \%$} \\
\hline & Rhodamin B & \multicolumn{2}{|c|}{$1,17 \%$} & \multicolumn{2}{|c|}{$1,67 \%$} \\
\hline & Methanil Yellow & \multicolumn{2}{|c|}{$0,39 \%$} & \multicolumn{2}{|c|}{$1,37 \%$} \\
\hline & Pestisida & \multicolumn{2}{|c|}{$0,00 \%$} & \multicolumn{2}{|c|}{$0,05 \%$} \\
\hline & Total & \multicolumn{2}{|c|}{$4,35 \%$} & \multicolumn{2}{|c|}{$5,67 \%$} \\
\hline
\end{tabular}

(Sumber : Dinkes; Dinperpa; dan Dindagkop \& UKM Kota Pekalongan, 2018-2019)

Berdasarkan tabel 1 di atas dapat diketahui bahwa sebanyak $80 \%$ dari total sampel pangan yang dilakukan pemeriksaan uji BTP berbahaya pada tahun 2018-2019, paling banyakdiperoleh dari lingkungan sekolah. Sekolah sebagai sarana pendidikan belajar mengajar, idealnya sekolah merupakan tempat yang aman dari peredaran pangan yang mengandung BTP berbahaya. Hasil penelitian ini menunjukan hal yang berbeda yakni diketemukannya peredaran pangan mengandung BTP berbahaya, 3,42\% pada tahun 2018 dan $4,60 \%$ pada tahun 2019 pangan yang beredar mengandung BTP berbahaya.

Penelitian ini diperkuat dengan hasil penelitian Nuraini (2016) yang menyatakan bahwa 8,3\% Pangan Jajan Anak Sekolah (PJAS) mengandung borak, sedangkan BTP berbahaya seperti formalin dan Rhodamin $B$ tidak diketemukan pasa sampel pangan yang 
diuji. Artinya di lingkungan sekolah tersebut masih ada/masih diketemukan pedagang yang menjual pangan yang mengandung BTP berbahaya entah disengaja atau tidak. Hasil penelitian ini juga diperkuat dengan temuan ini BPOM di Semarang tahun 2018 hasil pengawasan pangan sampel Pangan Jajan Anak Sekolah (PJAS) sebanyak 718 sampel di 24 kota/kabupaten, $0,975 \%$ mengandung BTP berbahaya, artinya terindikasi bahwa 24 kota/kabupaten beredar pangan jajan anak sekolah yang mengandung BTP berbahaya.

Bertolak belakang dengan penelitian Nurdin dan Utomo (2018) yang dalam penelitiannya menyatakan bahwa tidak ditemukan bahan tambahan pangan berbahaya untuk semua sampel yang diteliti. Sehingga jajanan anak di sekolah area Sidorejo Kidul, Kecamatan Tingkir, Kota Salatiga masih dapat dikatakan aman untuk dikonsumsi. Hal ini dimungkinkan karena penelitian yang dilakukan hanya pada tingkatan sekolah dasar saja, dan jumlah sampel yang diperiksa lebih sedikit. Sedangkan pada penelitian ini lokasi yang menjadi sasaran adalah semua sekolahan dari mulai tingkatan SD dan MI hingga tingkatan SMA/K dan MA, serta lokasi lain seperti pasar tradisional dan event keramaian kota. Hal ini diperkuat juga dengan jumlah sampel yang diperiksa lebih banyak.

Tahun 2018 jenis sampel pangan yang diuji, sampel pangan positif mengandung BTP berbahaya yang diketemukan adalah jenis pengawet boraks $1,01 \%$ dan formalin $1,79 \%$, sedangkan jenis pewarna Rhodamin B $1,17 \%$ dan Methanil Yellow 0,39\%. Tahun 2019 jenis pengawet boraks $0,30 \%$ dan formalin 2,28\%, sedangkan jenis pewarna Rhodamin B 1,67\% dan Methanil Yellow 1,37\%. Tahun 2019 diketemukan pangan selain mengandung BTP berbahaya seperti pengawet dan pewarna, diketemukan juga pangan mengandung pestisida sebesar $0,05 \%$.

Tabel 2 Persentase Jenis Pangan Positif Mengandung Bahan Tambahan Pangan Berbahaya di Kota Pekalongan Tahun 2018-2019

\begin{tabular}{|c|c|c|c|c|}
\hline \multirow[b]{2}{*}{ No } & \multirow[b]{2}{*}{ Jenis Pangan } & \multirow[b]{2}{*}{ Sub Jenis Pangan } & \multicolumn{2}{|c|}{ Prosentase (\%) } \\
\hline & & & $\begin{array}{c}\text { Tahun } \\
2018\end{array}$ & $\begin{array}{c}\text { Tahun } \\
2019\end{array}$ \\
\hline \multirow[t]{4}{*}{1} & \multirow[t]{4}{*}{ Bahan Dasar Mie } & Mie goreng & 3,57 & 4,46 \\
\hline & & Mie kuning & 10,71 & 14,29 \\
\hline & & Mie Gulung & - & 1,79 \\
\hline & & Nuget mie & - & 0,89 \\
\hline \multirow[t]{9}{*}{2} & \multirow[t]{9}{*}{ Bahan Dasar Tahu } & Tahu balado & - & 0,89 \\
\hline & & Tahu bulat & - & 0,89 \\
\hline & & Tahu crispi & 3,57 & - \\
\hline & & Tahu goreng & - & 1,79 \\
\hline & & Tahu kopyok & - & 0,89 \\
\hline & & Tahu kulit & - & 0,89 \\
\hline & & Tahu bacem & 1,78 & - \\
\hline & & Tahu putih & 1,78 & 2,68 \\
\hline & & Tahu sakura & 0,00 & 1,79 \\
\hline \multirow[t]{3}{*}{3} & \multirow[t]{3}{*}{ Bumbu Masakan } & Tepung panir & - & 0,89 \\
\hline & & Bumbu bubuk & - & 6,25 \\
\hline & & Mesis & - & 0,89 \\
\hline \multirow[t]{2}{*}{3} & \multirow[t]{2}{*}{ Bumbu Masakan } & Tepung panir & - & 0,89 \\
\hline & & Biting bumbu bubuk & - & 0,89 \\
\hline \multirow[t]{8}{*}{4} & \multirow[t]{8}{*}{ Kripik dan Krupuk } & Contong es merah & - & 0,89 \\
\hline & & Intip & 1,78 & \\
\hline & & Krupuk Gendar & - & 0,89 \\
\hline & & Krupuk rambak & 3,57 & - \\
\hline & & Krupuk tepi kuning & - & 2,68 \\
\hline & & Krupuk tepi merah & 3,57 & 1,79 \\
\hline & & Krupuk useg kuning & - & 5,36 \\
\hline & & Krupuk useg merah & 3,57 & 10,71 \\
\hline \multirow[t]{4}{*}{4} & \multirow[t]{4}{*}{ Kripik dan Krupuk } & Krupuk usus & - & 1,79 \\
\hline & & Makaroni goreng & 1,78 & 0,89 \\
\hline & & Mie Biting & 1,78 & - \\
\hline & & Opak angin & 1,78 & - \\
\hline
\end{tabular}

Lanjutan Tabel.2. ... 


\begin{tabular}{|c|c|c|c|c|}
\hline \multirow[b]{2}{*}{ No } & \multirow[b]{2}{*}{ Jenis Pangan } & \multirow[b]{2}{*}{ Sub Jenis Pangan } & \multicolumn{2}{|c|}{ Prosentase (\%) } \\
\hline & & & $\begin{array}{c}\text { Tahun } \\
2018\end{array}$ & $\begin{array}{c}\text { Tahun } \\
2019\end{array}$ \\
\hline 5 & Minuman & Minuman & 3,67 & 1,77 \\
\hline \multirow[t]{11}{*}{6} & Olahan daging dan & Bakso, indil dan cilok & 14,27 & 3,57 \\
\hline & olahan ikan & Cireng & 1,78 & 0,89 \\
\hline & & Gereh sotong & - & 0,89 \\
\hline & & Nuget & 1,78 & 1,79 \\
\hline & & Otak-otak & 5,35 & - \\
\hline & & Scalep & - & 0,89 \\
\hline & & Sempolan & 3,57 & - \\
\hline & & Sosis & 1,78 & 2,68 \\
\hline & & Sosis gulung mie & - & 0,89 \\
\hline & & Tahu bakso & 1,78 & 0,89 \\
\hline & & Teri nasi (teri medan) & 5,35 & 1,79 \\
\hline \multirow[t]{5}{*}{7} & Permen & Arum manis & 1,78 & 2,68 \\
\hline & & Jipang & - & 0,89 \\
\hline & & Kembang kapas & - & 0,89 \\
\hline & & Permen karet & 1,78 & 0,89 \\
\hline & & Permen tengkorak & - & 0,89 \\
\hline \multirow[t]{2}{*}{8} & Sayur dan Buah & Manisan & - & 0,89 \\
\hline & & Tomat & - & 0,89 \\
\hline \multirow[t]{8}{*}{9} & Snack Basah & Agar-agar & 3,57 & 1,79 \\
\hline & & Ala nyam-nyam & 3,57 & - \\
\hline & & Kue ku & - & 1,79 \\
\hline & & Lumpia & - & 0,89 \\
\hline & & Martabak & 1,78 & 1,79 \\
\hline & & Mie gulung & - & 1,79 \\
\hline & & Pop corn & 1,78 & 0,89 \\
\hline & & Puding & 7,14 & 3,57 \\
\hline \multicolumn{3}{|c|}{ Jumlah } & $100 \%$ & $100 \%$ \\
\hline
\end{tabular}

(Sumber : Dinkes; Dinperpa; dan Dindakop \& UKM Kota Pekalongan, 2018-2019)

Berdasarkan tabel 2 di atas diketahui bahwa jenis pangan yang paling sering diketemukan positif mengandung BTP berbahaya dari total sampel pangan yang positif, pada tahun 2018 adalah pangan jenis : $14,27 \%$ bakso, indil dan cilok mengandung boraks; $10,71 \%$ mie kuning mengandung formalin; $7,14 \%$ puding mengandung Rhodamin B dan Methanil Yellow; 5,36\% teri nasi (teri medan) mengandung formalin; dan $5,36 \%$ otak-otak mengandung formalin dan Rhodamin B. Sedangkan pada tahun 2019 jenis pangan yang paling sering diketemukan mengandung BTP berbahaya adalah pangan jenis : $12,50 \%$ mie kuning mengandung formalin; $11,61 \%$ krupuk useg warna merah mengandung Rhodamin B; 6,25\% bumbu bubuk mengandung Methanil Yellow; dan 4,46\% krupuk useg warna kuning mengandung Methanil Yellow.

Idealnya pangan yang beredar/dijual haruslah memenuhi kriteria pangan, yakni: aman, bermutu dan bergizi. Pangan yang aman untuk dikonsumsi adalah pangan yang bebas dari cemaran fisik, cemaran biologi dan cemaran kimia. Salah satu aspek aman dari cemaran kimia adalah terbebas dari bahan tambahan pangan (BTP) berbahaya/dilarang ditambahkan pada pangan. Menurut Peraturan Daerah Kota Pekalongan Nomor 07 Tahun 2013 tentang Larangan Penggunaan Bahan Tambahan Pangan Berbahaya, keempat bahan kimia tersebut dilarang penggunaannya dalam produk pangan karena berbahaya bagi kesehatan.

\subsubsection{Formalin}

Formalin dilarang digunakan sebagai bahan tambahan pangan karena banyak dampak negatif yang ditimbulkan, seperti yang dipaparkan Eka (2013) seperti dikutip Yulisa et al (2014) bahwa formalin dalam pangan dapat menyebabkan keracunan dengan tanda gejala sakit perut disertai dengan muntah dan diare, serta dapat menyebabkan depresi susunan saraf dan dapat menyebabkan perubahan sel dan jaringan tubuh.

\subsubsection{Boraks}

See (2010) dalam Istiqomah, et al, (2016), memaparkan untuk konsumsi pangan yang mengandung boraks sangat bersiko bagi kesehatan dan dapat mematikan sel, kelainan susunan saraf, depresi dan gangguan mental. 


\subsubsection{Rhodamin $B$}

Wijaya (2011) dalam Laksmita, et al, (2018) menerangkan bahwa Rhodamin $B$ memberikan pengaruh buruk bagi kesehatan antara lain menimbulkan iritasi saluran pernapasan, kulit, mata, dan saluran pencernaan, gangguan fungsi hati berupa kanker hati dan tumor hati.

\subsubsection{Methanyl Yellow}

Yusuf (2011) dalam kutipan Sahani dan Yuni (2017) menerangkan bahwa dampak negatif yang ditimbulkan akibat mengonsumsi pangan yang mengandung Methanil Yellow yaitu menyebabkan iritasi saluran cerna, mual, muntah, sakit perut, diare dan kanker pada saluran kemih dan kandung kemih.

Hasil penelitian ini diperkuat dengan penelitian yang dilakukan oleh Paratmanitya dan Aprilia (2016) juga menyatakan bahwa jenis makanan diduga mengandung bahan kimia berbahaya paling banyak dijajakan di SD se Kabupaten Bantul adalah jenis bakso (bakso, bakso tusuk, bakso goreng) yaitu sejumlah $22,4 \%$ dari seluruh sampel jajanan, di antara sampel yang diuji: $15,3 \%$ positif boraks; $25,5 \%$ positif formalin; 46,7\%) positif Rhodamin $B$. Lebih lanjut pendapat senada dikemukanan oleh Rofieq, et al (2017) menyimpulkan bahwa ada lima jenis BTP berbahaya pada jajanan di lingkungan SMA di Jawa Timur teridentifikasi, sedangkan satu jenis BTP tidak teridentifikasi, yaitu Methanil Yellow. Sampel pangan yang diuji 37,5\% mengandung BTP berbahaya yakni pengawet dan pewarna, untuk pemanis diizinkan tetapi nilainya melebihi ambang batas. Berdasarkan jenis, pangan mengandung BPT berbahaya, terbanyak krupuk dan minuman. Hal lain yang mendukung ataupun menguatkan penelitian ini adalah hasil kegiatan pengawasan keamanan pangan di Kota Pekalongan dilaksanakan secara resmi oleh OPD yang sesuai bidangnya, sampel pangan yang diperiksa jumlahnya banyak dan tidak hanya dilakukan di satu lokasi saja, tetapi di beberapa lokasi yang bervariasi.

Hasil penelitian ini merujuk jenis pangan yang paling sering diketemukan mengandung BTP berbahaya jenis pengawet adalah pangan jenis bakso, indil dan cilok; mie kuning; teri nasi (teri medan); dan otak-otak. Sedangkan merujuk jenis pangan yang paling sering diketemukan mengandung BTP berbahaya jenis pewarna adalah pangan jenis krupuk useg warna merah; bumbu bubuk; krupuk useg warna kuning; dan puding. Penambahan BTP berbahaya jenis pengawet (formalin dan boraks) kemungkinan karena jenis pangan tersebut merupakan jenis pangan yang akan cepat basi, cepat tengik dan berbau, sehingga apabila jenis pangan tersebut dijual dan tidak cepat habis terjual maka hal tersebut dapat merugikan penjual. Kemungkinan agar pangan tersebut tetap awet dalam jangka waktu lama, produsen pangan menambahkan BTP berbahaya tersebut ke dalam proses produksinya, seperti yang ada dalam penelitian ini bahwa jenis pangan yang paling sering dijumpai mengandung BTP berbahaya jenis pengawet adalah jenis: mie kuning; bakso, indil dan cilok; teri nasi (teri medan); dan otak-otak. Penambahan BTP berbahaya jenis pewarna (Rhodamin $B$ dan Methanil Yellow) kemungkinan ditambahkan pada pangan adalah untuk lebih menarik tampilan pangan. Kemungkinan penambahan BTP berbahaya jenis ini dalah memberikan warna yang lebih kuat, harga lebih murah sehingga mampu memberikan keuntungan lebih dalam penjualan. Seperti yang ada dalam penelitian ini bahwa jenis pangan yang paling sering diketemukan mengandung BTP berbahaya jenis pewarna adalah jenis: krupuk useg warna merah, bumbu bubuk, krupuk useg warna kuning dan puding.

Jenis pangan yang mengandung BTP berbahaya tersebut sebetulnya dapat dikenali secara fisik. Pangan yang mengandung BTP berbahaya pengawet (formalin dan boraks) dapat dilihat memiliki ciri : tekstur lebih kenyal (pada bakso, indil dan cilok; dan otak-otak), warna cenderung pucat keabu-abuan (pada bakso, indil dan cilok), lebih elastis/ tidak cepat putus jika ditarik (pada mie kuning), tidak dihinggapi lalat (pada jenis teri nasi dan bakso), berbau tidak normal/bukan khas bau pangan dan memiliki waktu simpan lebih dari 4-6 jam (pada mie kuning)/waktu simpan lebih dari 1-2 hari (pada jenis bakso, indil dan cilok; dan otakotak) atau sampai beberapa bulan pada teri nasi (teri medan). Pangan yang mengandung BTP berbahaya pewarna (Rhiodamin B dan Methanil 
Yellow) dapat dilihat memiliki ciri: warna pangan yang cenderung berpendar (pada snack dan minuman) dan memberikan titik-titik warna pada pangan karena tidak homogen (pada krupuk).

4.2. Implementasi Peraturan Daerah Kota Pekalongan Nomor 07 Tahun 2013 tentang Larangan Penggunaan Bahan Tambahan Pangan Berbahaya

Menurut informan utama, 3 dari 4 informan menyatakan bahwa informan utama sudah mengetahui tentang Perda tersebut secara garis besarnya saja walaupun tidak secara mendetail. Semua informan utama mampu mendeskripsikan pekerjaannya terkait kegiatan kemanan pangan dan semua informan utama menyatakan sudah mengimplementasikan Perda tersebut.

Menurut informan pendamping, 8 dari 9 informan menyatakan sudah pernah tersosialisasi tentang Perda tersebut seperti Dinas Kesehatan ataupun Dinas Perdagangan Koperasi \& UKM ataupun tidak langsung yang diperoleh dari sesama produsen pangan dan dari salah satu keluarga yang pernah tersosialisasi.

Menurut informan triangulasi, kelompok pelaksana lapangan menyatakan bahwa mereka sedikit mengetahui mengenai Perda Kota Pekalongan Nomor 7 Tahun 2013 tentang Larangan Penggunaan Bahan Tambahan Pangan Berbahaya, akan tetapi mereka sudah mengimplementasikan dalam pekerjaan secara rutin. Menurut informan triangulasi kelompok pelaksana lapangan, ada dukungan dari Pemerintah Kota Pekalongan berupa dukungan anggaran dan prasarana, tetapi kurang dalam pemberian sanksi bagi pelanggar. Menurut informan triangulasi kelompok masyarakat umum, menyatakan tidak tahu tentang Perda tersebut, tetapi menurut informan triangulasi keberadaan Perda ini penting karena agar masyarakat aman membeli pangan untuk konsumsi.

Berdasarkan pola jawaban para informan penelitian dapat diketahui bahwa Peraturan Daerah Kota Pekalongan Nomor 07 Tahun 2013 tentang Larangan Penggunaan Bahan Tambahan Pangan berbahaya, sudah diimpelementasikan dengan baik dalam bentuk kegiatan sosialisasi keamanan pangan dan pengawasan keamanan pangan yang beredar secara berkala, namun belum optimal karena belum ada penegakan sanksi bagi pelanggar Perda. Seharusnya pemerintah daerah bisa melindungi warganya dari peradaran pangan yang tidak aman, salah satunya adalah pangan aman dari cemaran bahan kimia berbahaya yang dapat berupa cemaran BTP berbahaya atau cemaran bahan kimia lainnya. Pangan yang tidak aman/tercemar BTP berbahaya dapat merugikan masyarakat yakni berupa munculnya gangguan kesehatan pada tubuhnya, kerena itu perlindungan terhadap masyarakat terhadap pangan yang mengandung BTP berbahaya sangatlah penting.

Hasil penelitian ini hampir sejalan, namun sedikit berbeda dengan yang sudah diteliti oleh Anggiarini, et al (2018) menyatakan bahwa Kebijakan Pemerintah Daerah Kabupaten Jepara terkait kemanan pangan tertuang dalam Renstra Dinkes Kabupaten Jepara yaitu Pembinaan dan Pengawasan Pangan di Lingkungan Sekolah. Perbedaan pada penelitian ini kebijakan/peraturan daerah yang mengatur tentang keamanan pangan sudah ada yakni adanya Peraturan Daerah Kota Pekalongan Nomor 07 Tahun 2013 tentang Larangan Penggunaan Bahan Tambahan Pangan Berbahaya.

Hasil penelitian ini diketahui bahwa, Pemerintah Kota Pekalongan sudah mengupayakan perlindungan bagi warganya dari peredaran pangan tidak aman dengan menerbitkan Peraturan Daerah Kota Pekalongan Nomor 07 Tahun 2013 tentang Larangan Penggunaan Bahan Tambahan Pangan Berbahaya. Implementasi Perda tersebut sudah diimplementasikan dengan baik, namun belum optimal dalam sosialisasi keamanan pangandan penegakan sanksi yang tegas terhadap pelanggar Perda.

4.3. Pengetahuan Dan Sikap Produsen Dalam Memproduksi Pangan Yang Aman di Kota Pekalongan

Menurut informan utama, 3 dari 4 informan utama menyatakan bahwa produsen pangan/pedagang pangan sudah mengetahui tentang bahaya penggunaan BTP berbahaya yang termuat dalam Peraturan Daerah Kota Pekalongan Nomor 07 Tahun 2013 tentang 
Larangan Penggunaan Bahan Tambahan Pangan Berbahaya, tetapi salah satu informan utama menyatakan bahwa produsen pangan/pedagang pangan belum mengetahui tentang bahaya penggunaan BTP berbahaya pada pangan.

Menurut informan pendamping 7 dari 9 , informan pendamping menyatakan mengetahui tentang pangan yang aman adalah yang tidak ada campuran bahan kimia. Penggalian lebih mendalam terhadap informan pendamping diperoleh jawaban bahwa dari 9 informan hanya 1 yang benar-benar tahu tentang BTP berbahaya, sedangkan sisanya tidak dapat menyebutkan jenis-jenis BTP berbahaya yang dilarang. Menurut informan pendamping, bahwa pangan yang aman adalah yang tidak mengandung bahan kimia, tetapi belum mampu menyebutkan ciri pangan yang mengandung BTP berbahaya seperti apa dan bahayanya apa.

Menurut informan triangulasi, baik dari kelompok pelaksana lapangan, pedagang kecil dan masyarakat umum, 10 dari 12 informan menyatakan bahwa pedagang mengetahui pangan yang aman itu seperti apa, tetapi 2 informan menyatakan bahwa pedagang sudah tahu pangan yang aman/tidak seperti apa, tetapi sikapnya sengaja tetap menjual pangan tidak aman agar memperoleh keuntungan lebih.

Secara ideal produsen pangan akan mengetahui proses produksi pangan yang aman apabila sudah memperoleh informasi tentang pangan dan keamanan pangan baik melalui sosialisasi yang dilaksanakan oleh pemerintah ataupun memperoleh informasi dari sumbersumber lain. Setelah produsen pangan mengetahuinya, kemudian ke tahapan selanjutnya adalah mau dan mampu, artinya adalah mau memproduksi pangan aman, dan mampu menerapkannya dalam proses produksi pangan.

Hasil penelitian ini diperkuat dengan penelitian dari Handayani dan Hartono (2016) yang menyatakan bahwa adanya hubungan antara pengetahuan dengan sikap penggunaan BTP berbahaya, serta pengetahuan yang mayoritas baik didapatkan pangan yang disajikan di kantin sekolah tidak menggunakan BTP berbahaya.
Hasil penelitian ini diperoleh bahwa pengetahuan produsen pangan/pedagang pangan sebagian sudah mengetahui tentang pangan dan keamanan pangan, bahkan beberapa di antaranya sudah memperoleh informasi tentang pangan dan keamanan pangan secara resmi dari OPD terkait. Dalam penerapan proses produksi pangan keseharian sebagian produsen pangan/pedagang pangan sudah mau dan mampu menerapkan informasi yang diperoleh, dengan tidak menggunakan BTP berbahaya yang merugikan kesehatan.

\section{KESIMPULAN DAN SARAN}

\subsection{Simpulan}

Berdasarkan hasil dan pembahasan yang sudah dilakukan, maka dapat disimpulkan bahwa :

a) Pangan paling sering diketemukan mengandung BTP berbahaya pengawet (formalin dan boraks) adalah jenis mie kuning (mie basah); bakso, indil dan cilok; teri nasi (teri medan); dan otak-otak. Pangan paling sering diketemukan mengandung BTP berbahaya pewarna (Rhodamin $B$ dan Methanil yellow) adalah krupuk useg warna merah; puding; bumbu bubuk; dan krupuk useg warna kuning.

b) Peraturan Daerah Kota Pekalongan Nomor 07 Tahun 2013 tentang Larangan Penggunaan Bahan Tambahan Pangan berbahaya sudah diimplementasikan, namun belum optimal dalam sosialisasi keamanan pangan, penegakan sanksi yang tegas terhadap pelanggar perda dan koordinasi dengan pemerintah daerah lain.

c) Pengetahuan dan sikap produsen dalam memproduksi pangan yang aman di Kota Pekalongan bahwa pengetahuan produsen pangan/pedagang pangan sebagian sudah mengetahui tentang keamanan pangan. Sebagain produsen pangan/pedagang pangan sudah mau dan mampu memproduksi pangan yang aman, yang dikuatkan dengan sudah ada izin produksi.

\subsection{Saran}

Berdasarkan penarikan kesimpulan yang ada, maka dapat disarankan sebagai berikut:

a) Pemerintah Kota Pekalongan, melalui Bappeda Kota Pekalongan, disarankan dapat 
melakukan sosialisasi elaboratif tentang keamanan pangan pada dinas terkait dan lintas sektor.

b) Materi yang dapat diberikan pada saat sosialisasi elaborasi keamanan pangan dapat berupa: (1) Peningkatan kapasitas petugas pelaksana pengawasan keamanan pangan dapat disampaikan kepada Dinkes, Dinperpa, Dindakop \& UKM Kota Pekalongan; (2) Dampak bahaya pangan mengandung bahan tambahan pangan berbahaya dan sanksi hukum; (3) Jenis-jenis bahan tambahan pangan berbahaya; dan (4) Ciri pangan mengandung bahan tambahan pangan berbahaya dan bahayanya bagi kesehatan.

c) Kota Pekalongan melalui Bappeda Kota Pekalongan, menjalin komunikasi efektif dengan pemerintah daerah lain di sekitar Kota Pekalongan untuk dapat melakukan pengawasan keamanan pangan.

d) Produsen pangan yang belum memperoleh informasi tentang keamanan pangan, dapat mengajukan permohonan sosialisasi atau peningkatan kapasitas pengetahuan tentang keamanan pangan pada Puskesmas, Dinas Kesehatan, Dinas Pertanian dan Pangan ataupun Dinas Perdagangan Koperasi \& UKM.

\section{DAFTAR PUSTAKA}

Anggiarini, N.A., L. Hanim, dan U. Ma'ruf. 2018. Studi Pelaksanaan Kebijakan Pemerintah Daerah Terkait Bahan Tambahan Pangan Pada Jajanan Anak Sekolah Menurut Permenkes No. 033 Tahun 2012 di Kabupaten Jepara. Semarang. Jurnal Hukum Khaira Ummah Volume 13 (1), Maret 2018 : 215 - 228. (online). Diunduh tanggal 26 September 2018. http://jurnal.unissula.ac.id.

Anggrahini, S. 2015. Kemanan Pangan. Jakarta. PT Kasinus

Athaya, Z. R., E. Elmatris, dan H. Kadri. 2015. Identifikasi Boraks pada Cincau Hitam yang Diproduksi Beberapa Produsen Cincau Hitam di Kota
Padang. Padang. Jurnal Kesehatan Andalas Volume 3 (1), Tahun 2015: 37-40 . Diunduh tanggal 10 Agustus 2020. http://jurnal.fk.unand.ac.id

BPOM di Semarang. 2017. Modul Pendidikan dan Pelatihan Fungsional Penyuluh Keamanan Pangan Tahun 2017. Semarang. BPSDM Prov Jateng.

2019 Laporan Tahunan BPOM di Semarang Tahun 2018. Badan Pengamanan Obat dan Makanan Republik Indonesia. https://pom.go.id, diakes tanggal 02 Februari 2020.

Dinkes Kota Pekalongan. 2011. Laporan Tahunan Dinas Kesehatan Kota Pekalongan Tahun 2010. Dinas Kesehatan Kota Pekalongan

Tahunan Dinas Kesehatan Kota Pekalongan Tahun 2011. Dinas Kesehatan Kota Pekalongan

\section{Laporan}

Tahunan Dinas Kesehatan Kota Pekalongan Tahun 2012. Dinas Kesehatan Kota Pekalongan

Handayani, S, dan H. Hartono. 2016. Hubungan Pengetahuan Guru dan Pengelola Kantin Tentang Gizi BTP, Terhadap Penggunaan BTP Beresiko pada Makanan Anak SD di Surakarta. Jurnal Terpadu Ilmu Keehatan, Volume 5 (2) Tahun 2016: 110-237. http://jurnal.poltekkes-solo.ac.id

Istiqomah, S., M.B Sudarwanto, dan E. Sudarnika 016. Penambahan Boraks dalam Bakso dan Faktor Pendorong Penggunaannya Bagi Pedagang Bakso di Kota Bengkulu. Jurnal Sain Veteriner,Volume 34 (1) Tahun 2016. Diunduh tanggal 10 Agustus 2020. http://jurnal.ugm.ac.id 
Laksmita, A.S.W., N.P Widayanti, dan M.A.F Refi.2018. Identifikasi Rhodamin B Dalam Saus Sambal yang Beredar Di Pasar Tradisional Dan Modern Kota Denpasar. Jurnal Media Sains Volume 2 (1) Tahun 2018: 813.http://jurnal.undhirabali.ac.id

Nuraini, S. 2016. Analisis Kandungan Bahan Tambahan Dilarang Pada Pangan Jajanan Anak Sekolah (PJAS) di Sekolah Dasar Kecamatan Rajabasa Kota Bandar Lampung. Jurnal Analis Kesehatan,Volume 5 (1) Tahun 2016: 490-493. http://ejournal.poltekkes-tjk.ac.id

Nurdin, N, dan U. Budi. 2018. Tinjauan Penggunaan Bahan Tambahan Pangan Pada Makanan Jajanan Anak Sekolah. Jurnal Riset Kesehatan, Volume 7 (2) Tahun 2018: 85-90. Diunduh tanggal 31 Oktober 2019. http://ejournal.poltekkes-smg.ac.id

Paratmanitya, Y, dan V. Aprilia. 2016. Kandungan bahan tambahan pangan berbahaya pada makanan jajanan anak sekolah dasar di Kabupaten Bantul. Jurnal Gizi dan Dietetik Indonesia, Volume 4 (1) Tahun 2016: 49-55. Diunduh Tanggal 31 Oktober 2019. http://ejournal.almaataa.ac.id

Peraturan Badan Pengamanan Obat dan Makanan Nomor 11 Tahun 2019 Bahan Tambahan Pangan. 01 Juli 2019. Berita Negara Republik Indonesia Tahun 2019 Nomor 723. Jakarta

Peraturan Daerah Kota Pekalongan Nomor 07 Tahun 2013 Larangan Penggunaan Bahan Tambahan Pangan Berbahaya. 29 Juli 2013. Lembaran Daerah Kota Pekalongan Tahun 2013 Nomor 7. Kota Pekalongan
Peraturan Menteri Kesehatan Republik Indonesia Nomor 33 Tahun 2012 Bahan Tambahan Pangan. 01 Maret 2012. Lembaran Negara republik Indonesia Tahun 2012 Nomor 58. Jakarta

Peraturan Pemerintah Republik Indonesia Nomor 86 Tahun 2019 Kemanan Pangan. 26 Desember 2019. Lembaran Negara republik Indonesia Tahun 2019 Nomor 249. Tambahan Lembaran Negara Republik Indonesia Tahun 2019 Nomor 6442. Jakarta

Radar Pekalongan. 2019. Produksi Mie Basah Berformalin Diungkap. Sabtu, 14 Desember 2019.

Rahayu, P.W, dan I. Susalit. 2018. Keamanan Pangan Kepedulian Kita Bersama. Bogor. PT Penerbit IPB Perss.

Rofieq, A., E.P. Dewangga, dan M.H Lubis. 2017. Analisis Bahan Tambahan Pangan Berbahaya Dalam Jajanan Di Lingkungan Sekolah Menengah Atas Propinsi Jawa Timur Indonesia. Prosiding Seminar Nasional III Tahun 2017Universitas Muhamadiyah Malang "Biologi, Pembelajaran, dan Lingkungan Hidup Perspektif Interdisipliner": 75-83. Malang, 29 April 2017. Diunduh tanggal 09 Oktober 2018. http://research-report.umm.ac.id

Sahani .W, dan J. Yuni. 2017. Kandungan Zat Pewarna Metanil Yellow pada Tepung Panir yang Dijual di Pasar Tradisional Kota Makassar. Jurnal Sulolipu : Media Komunikasi Sivitas Akademika dan Masyarakat Volume 17 (1) Tahun 2017: 56-59. Diunduh tanggal 10 Agustus 2020. http://journal.poltekkes-mks.ac.id

Surono, I.S., A. Sudibyo, dan P. Waspodo. 2018. Pengantar Keamanan Pangan 
untuk Industri. Yogyakarta. Penerbit

Deepublish

Undang-undang Republik Indonesia Nomor 18

Tahun 2012 Pangan. 16 November 2012. Lembaran Negara republik Indonesia Tahun 2012 Nomor 227. Jakarta

Yulisa, N.Y., E. Asni, dan M. Azrin. 2014. Uji Formalin pada Ikan Asin Gurami di Pasar Tradisional Pekanbaru. Jom FK Volume 1 (2) Oktober 2014. Diunduh tanggal 10 Agustus 2020. https://media.neliti.com

Zuraida, R., O. Saputra., Z. Sahli, dan A.Aprilia2017. Faktor-Faktor yang Mempengaruhi Pedagang Jajanan Anak Sekolah Dasar terhadap Penggunaan Pewarna Metanil Yellow di Kecamatan Sukarame Bandar Lampung Tahun 2015. Jurnal Kesehatan dan Agromedicine Volume 4 (1). Tahun 2017. https://juke.kedokteran.unila.ac.id 